\title{
The influence of large wood and rootwad on flow patterns and bed morphology in a moving bed channel
}

\author{
Su-Chin Chen ${ }^{1}$, Min-Chih Liang ${ }^{1}$ and Samkele Tfwala ${ }^{1, *}$ \\ ${ }^{1}$ Department of Soil and Water Conservation, National Chung Hsing University, 145 Xingda Road, 402, \\ Taichung, Taiwan
}

\begin{abstract}
Studying large wood in river channels can help gain insight on their form and processes. Over the preceding decade, laboratory and field experiments have been used to explain wood dynamics, flow patterns and sediment transport. Moreover, field experiments are sparse, while laboratory experiments have focused mostly on fixed bed to capture their entrainment. To enhance our scientific understanding on logs of different morphology, this study designed an experimental flume to investigate the effects of log presence on flow and bed topography in a moving bed channel. Two log configurations were used, with and without rootwad. Wood pieces had a length of $0.2 \mathrm{~m}$, diameter $0.05 \mathrm{~m}$ and a density of approximately $760 \mathrm{~kg} / \mathrm{m}^{3}$. Rootwad were simulated by joining $0.06 \mathrm{~m}$ wood pieces, having a diameter of $0.02 \mathrm{~m}$ to the base of the log pieces at an angle of $30^{\circ}$. The experiments were carried out in a $4 \mathrm{~m}$ long flume, $0.6 \mathrm{~m}$ width and $0.6 \mathrm{~m}$ deep, and having a slope of 0.001 . The experimental bed zone was paved with uniform sand, $\mathrm{d}_{50}=0.750 \mathrm{~mm}$, of $0.1 \mathrm{~m}$ thickness. Flow in the channel was set such that it was below the critical flow for wood entrainment, and it ranged between 0.0015 to $0.005 \mathrm{~m}^{3} / \mathrm{s}$. Three different orientations of the log were considered, namely parallel, oblique and transverse to flow. Bed evolution was monitored using a camera and a laser mounted on a moving motor frame. This research shows that log orientation and the presence of rootwad dictate bed elevation changes and stability of single wood pieces. In addition, the contrast of morphological changes caused by the presence of abundant wood in a moving bed is crucial in determining large wood appropriate for river restoration. Our study provokes fascinating questions for future investigations.
\end{abstract}

\section{Introduction}

In many river systems, large wood debris is naturally occurring and are introduced by several recruiting processes including debris flow, landslides, bank erosion, etc. Taiwan provides a special case for wood dynamics due frequent land sliding and extreme tropical storms [1], which suggests their continuous supply. Conflicts have emerged over the years in regard to

\footnotetext{
* Corresponding author: samkelet@gmail.com
} 
their management; should large wood be removed in streams or should it be added? From an engineering point of view, fears were mainly on their potential in aggravating the consequences of flood events [2]. Moreover, their transport in rivers alters flow patterns; thus, play a crucial role in long term river dynamics due to their influence on the erosion process [3]. In addition, they can either act individually or collectively as physical obstruction and these will influence their pattern of the erosion-deposition process. Commonly in rivers, in-channel logs are deposited on top of gravel bars, while single log pieces are deposited on channel margins [4]. Since large wood has been shown to shape channel morphology [5], thus governing ecological diversity, many managers are now adding wood to stream channels as part of river restoration projects [6,7]. Moreover, for such projects to be successful an in depth understanding of how wood influences morphology is crucial. More fundamentally, an improved understanding of how this process can influence geo-morphodynamics with wood of different configurations is necessary.

Considerable research on large wood debris has been undertaken both in laboratory flume experiments and in the field. Among the earlier pioneers in the field, Braudrick and Grant [8] attempted to answer the question; when do logs move? Theoretical models of wood entrainment were developed through a series of flume experiments. They explored wood pieces with and without roots. Cylindrical wood pieces were also explored by Bocchiola, Rulli and Rosso [3], Crosato, et al. [9] etc. through flume studies. The aforementioned studies simplified the processes of wood dynamics by applying a fixed bed in their experimental channels, a condition different from the field. Large wood mobility has also been studied in the field such as Iroumé, et al. [10] who investigated wood movement over several time periods in Chilean rivers.

Large wood is often transported during storm events; hence, it is difficult to directly make observations during these events. Often, field surveys are conducted after such events by the use of remotely sensed data [11]. Flume experiments offer an opportunity to directly assess wood dynamics at a controllable scale. Substantial flume studies have employed fixed bed as already stated above, while others have explored simple wood configurations, i.e. smoothen wood [12]. A few studies have explored complex geometries such as rootwad in Davidson, et al. [13], Braudrick and Grant [8] etc. These studies applied complex geometries, their emphasis was wood dynamics and jam formations including incipient motions of the wood pieces. While our study used cylindrical logs, rootwad were added to capture the influence of roots in a mobile bed, a sparsely investigated field.

\section{Materials and methods}

\section{Experiment design}

A series of 8 flume experiments (Table 1) were conducted in a $11 \mathrm{~m}$ rectangular flume channel, having a $0.6 \mathrm{~m}$ width and depth, and 0.001 slope with the purpose of investigating the influence of wood on the bed channel. The channel was filled with $0.1 \mathrm{~m}$ thick layer of sand, having $\mathrm{d}_{50}$ of $0.750 \mathrm{~mm}$. Handmade logs with and without a rootwad were considered as illustrated in Fig. 1. A single type of wood was used. Its diameter $\left(d_{l o g}\right)$, length $\left(l_{l o g}\right)$ and dry density were respectively, $0.05 \mathrm{~m}, 0.2 \mathrm{~m}$ and $760 \mathrm{~kg} / \mathrm{m}^{3}$. The above $\log$ characteristics were chosen following a study by Shao, et al. [14] who investigated driftwood characteristics in Dajia river. The ratio $\left(d_{\log } / l_{\log }\right), 0.025$, for the investigated wood represented more than 
$70 \%$ of the wood downstream of this river. Measured in situ $d_{\log }$ and $l_{\log }$ were on average $300 \mathrm{~cm}$ and $75 \mathrm{~cm}$, respectively, translating to a scale ratio of 15:1. Three log orientations as shown in Fig. 1 were considered, they include parallel, oblique and transverse to flow. Rootwad were modelled by attaching $0.06 \mathrm{~m}$ wood pieces, which had a 0.02 diameter at an angle of $30^{\circ}$ (see Fig. 2 for wood installation in the flume. Flume runs were performed under steady conditions, and in each run, log was placed at a selected angle to flow while flow depth was gradually increased by adjusting the discharge. At a particular incremental discharge, 20 minutes were allowed to minimise unsteadiness, and this was continued until the discharge preceding log incipient initiation. There was no sediment feeding during the experimental runs. To allow fair comparison among the different orientations, the upper discharge limit was $0.00176 \mathrm{~m}^{3} / \mathrm{s}$ since in most orientations, logs began to move beyond this discharge. Mean flow velocity and flow depth at this discharge were $0.1931 \mathrm{~m} / \mathrm{s}$ and $1.5 \mathrm{~cm}$, respectively. In this study we do not discuss log incipient, the reader interested in $\log$ incipient or entrainment is referred to Bocchiola, Rulli and Rosso [3],Braudrick and Grant [8] and Davidson, MacKenzie and Eaton [13].

Table 1. Experimental conditions.

\begin{tabular}{cccc}
\hline Run & Orientation & Rootwad & Rootwad direction \\
\hline 1 & 0 & NA & NA \\
2 & 45 & NA & NA \\
3 & 90 & NA & NA \\
4 & 0 & Yes & Upstream \\
5 & 45 & Yes & Upstream \\
6 & 90 & Yes & Spanwise \\
7 & 0 & Yes & Downstream \\
8 & 45 & Yes & Downstream \\
\hline
\end{tabular}

To monitor bed elevation changes, a 3-dimension analysis method, laser scanning was used following the findings of Bertin and Friedrich [15] who compared 3D analysis tools and determined the aforementioned method best. The laser scan, MVnano series 2017 edition, was mounted such that it moved along the flume rails (indicated by grey lines in top view) as shown in the setup in Fig. 3. It covered $0.85 \mathrm{~m}$ in the longitudinal direction (of the experimental section), which was adequate to monitor topographic changes round the log. Topography was validated with a surface of known shape, and a standard error of $1 \mathrm{~mm}$ was attained. Scanned images were processed using an image processing toolbox, housed in MATLAB R2016b. All topographic measurements were done without water in the experimental flume. 


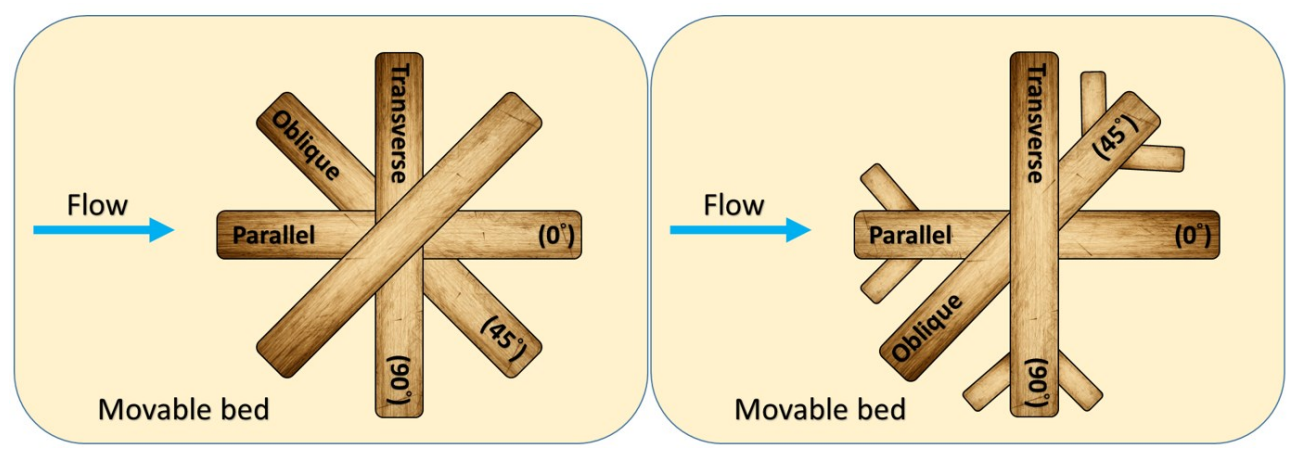

Fig. 1. Log setup
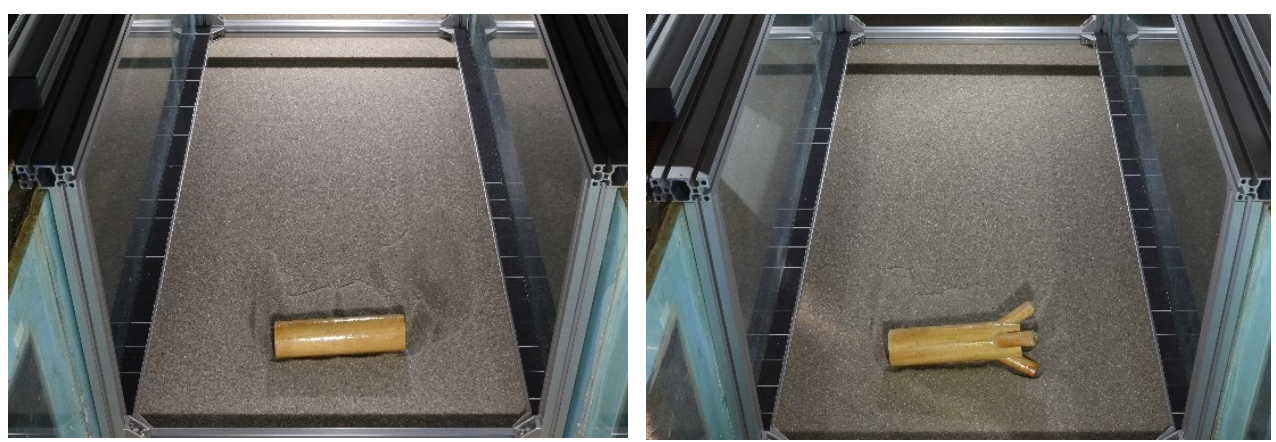

Fig. 2. An example of log installation, oriented transverse to flow in the flume, a) no rootwad and b) have rootwad

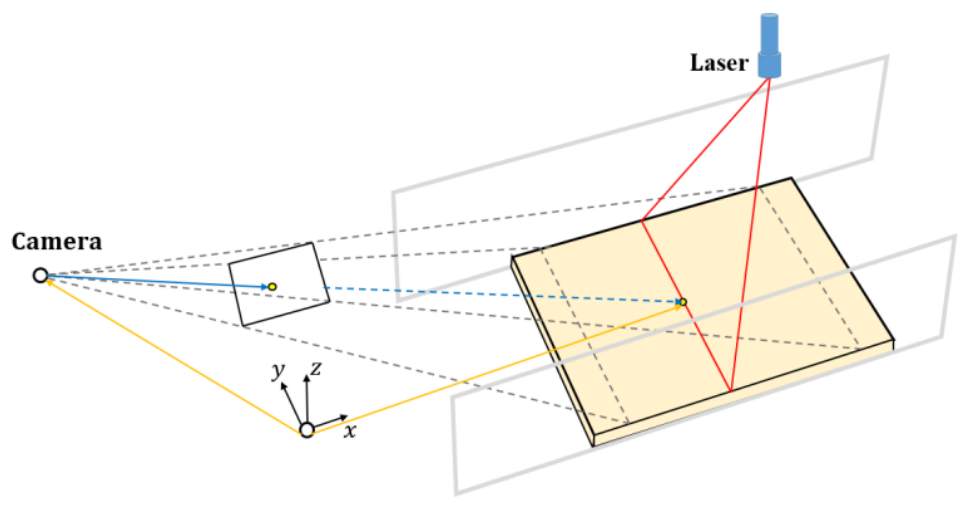

Fig. 3. Laser scan and camera setup.

\section{Results and discussion}

\section{Scour and deposition patterns}

We compared the spatial distribution of erosion and scour, and these are shown from Fig. 4 to Fig. 11. Generally, scour patterns may be grouped based on log orientation, presence and absence of roots. In addition, the patterns are highly correlated to their initiation of motion. An observation from flume experiments under fixed bed [3] conditions has shown different 
kinds of motion influence by the orientation of the log pieces to flow. Similar visual observations were made during the experimental runs. Logs oriented parallel to flow were most stable; hence, scouring would occur only at the close proximity as shown by Fig. 4 to Fig. 6.

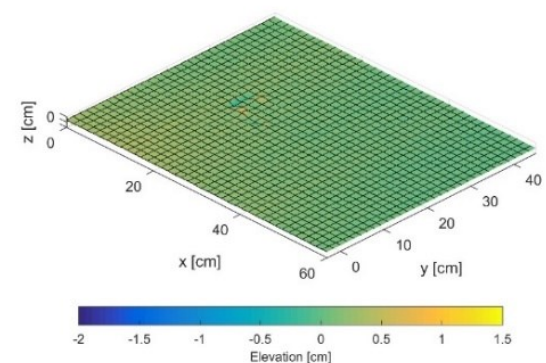

Fig. 4. Spatial distribution of scour and deposition, $0^{\circ}$, no rootwad.

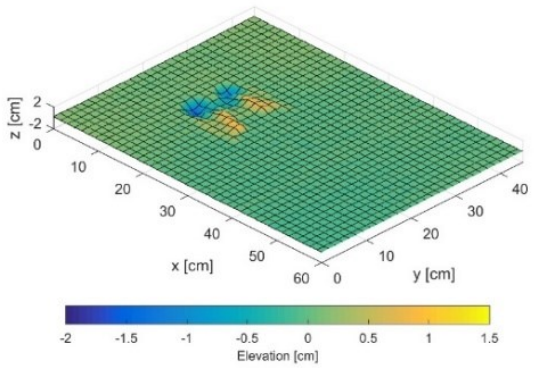

Fig. 6. Spatial distribution of scour and deposition, $0^{\circ}$, rootwad upstream

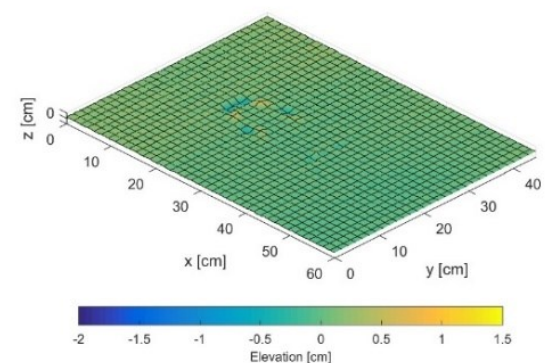

Fig. 5. Spatial distribution of scour and deposition, $0^{\circ}$, have rootwad downstream

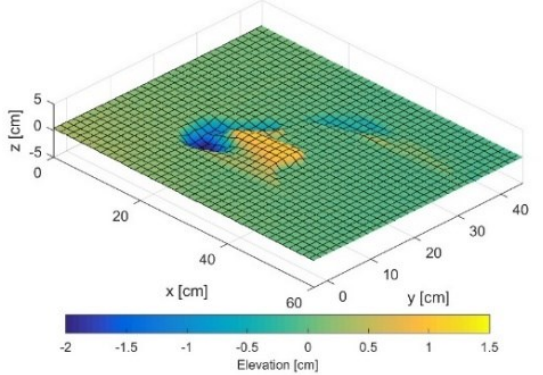

Fig. 7. Spatial distribution of scour and deposition, $45^{\circ}$, no rootwad.

Logs oriented oblique and transverse to flow, pivoting followed by slight rolling especially the transverse $\log$ for the latter case were observed. Pivoting was toward $90^{\circ}$ when the rootwad was attached at the upstream end (for $45^{\circ}$ ), while it was toward $0^{\circ}$ when the rootwad was attached at the downstream end. The slight pivoting and rolling movements are attributed to the larger surface area covered under this orientation. 


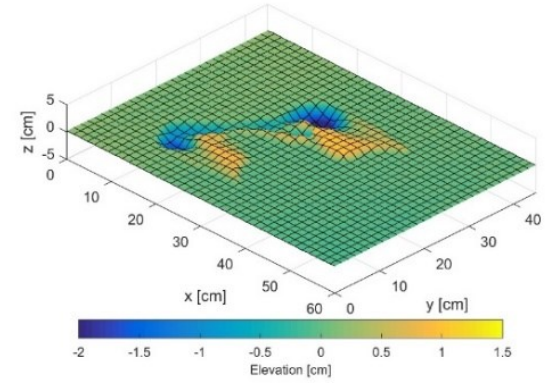

Fig. 8. Spatial distribution of scour and deposition, $45^{\circ}$, rootwad downstream

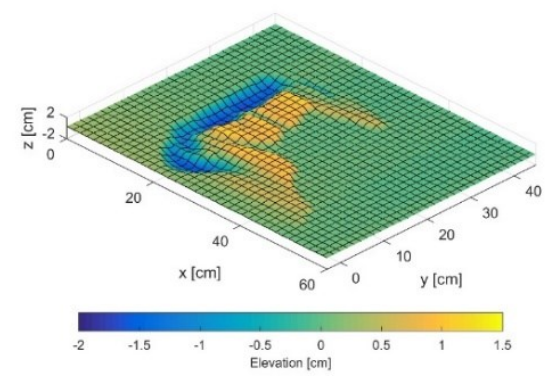

Fig. 10. Spatial distribution of scour and deposition, $90^{\circ}$, no rootwad.

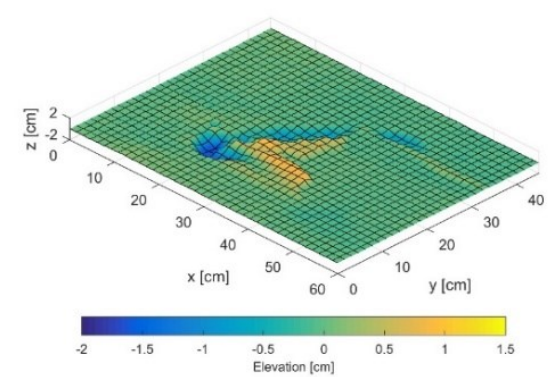

Fig. 9. Spatial distribution of scour and deposition, $45^{\circ}$, rootwad upstream

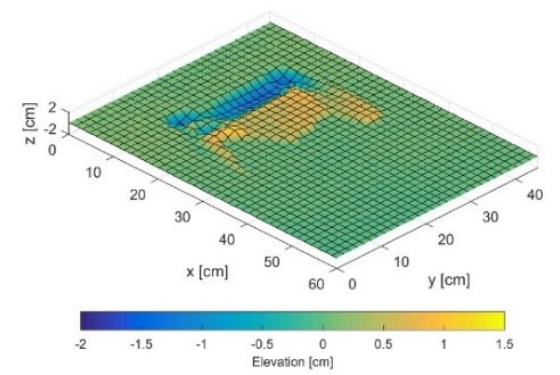

Fig. 11. Spatial distribution of scour and deposition, $90^{\circ}$, have rootwad.

\section{Scour and deposition volumes}

There is a lot of variation among the different log orientations. Logs oriented parallel to flow had the least scour volume $\left(1.78 \mathrm{~cm}^{3}\right)$, depth $(0.45 \mathrm{~cm})$ and deposition $\left(3.05 \mathrm{~cm}^{3}\right)$ volume, while logs oriented normal to flow had the highest scour $\left(236.69 \mathrm{~cm}^{3}\right)$ and deposition $\left(305.36 \mathrm{~cm}^{3}\right)$ volumes.

Logs where rootwad was attached had lesser volumes to their counterparts with no attachments. This could be explained by the reduction in the buoyancy force and the smaller $\log$ area exposed to flow as a result of the elevated logs. It should be noted that rootwad was attached at an angle of 30, with a length of $0.02 \mathrm{~m}$. This ratio between rootwad length and the log length could have a substantial impact as illustrated by $[8,16]$. In this study; nonetheless, we did not explore the different ratios in this regard. 
Table 2. Localised erosion and scour within the different experimental runs.

\begin{tabular}{rccccrrrr}
\hline Run & Orientation & $\begin{array}{c}\text { Rootwad } \\
\text { attachment }\end{array}$ & $\begin{array}{c}\text { Maximum } \\
\text { scour } \\
\text { depth } \\
(\mathrm{cm})\end{array}$ & $\begin{array}{c}\text { Maximum } \\
\text { deposition } \\
\text { height }(\mathrm{cm})\end{array}$ & $\begin{array}{c}\text { Scour area } \\
\left(\mathrm{cm}^{2}\right)\end{array}$ & $\begin{array}{c}\text { Deposition } \\
\text { area }\left(\mathrm{cm}^{2}\right)\end{array}$ & $\begin{array}{r}\text { scour } \\
\text { volume } \\
\left(\mathrm{cm}^{3}\right)\end{array}$ & $\begin{array}{c}\text { Deposition } \\
\text { volume } \\
\left(\mathrm{cm}^{3}\right)\end{array}$ \\
\hline 1 & 0 & NA & 0.45 & 0.50 & 26.95 & 22.74 & 1.78 & 3.05 \\
2 & 45 & NA & 2.23 & 1.28 & 189.23 & 277.67 & 105.84 & 109.53 \\
3 & 90 & NA & 1.93 & 1.32 & 279.40 & 653.39 & 236.69 & 305.36 \\
4 & 0 & Upstream & 1.73 & 0.99 & 69.19 & 104.82 & 34.32 & 33.67 \\
5 & 45 & Upstream & 1.97 & 0.99 & 195.47 & 232.71 & 93.812 & 79.63 \\
6 & 90 & Spanwise & 0.60 & 0.62 & 25.54 & 38.93 & 120.76 & 160.95 \\
7 & 0 & Downstream & 2.66 & 1.19 & 184.05 & 291.77 & 5.49 & 7.53 \\
8 & 45 & Downstream & 1.59 & 1.34 & 193.28 & 331.64 & 125.46 & 136.87 \\
\hline
\end{tabular}

\section{Conclusions}

This study has revealed localised scour and deposition as a result of log presence, which could be grouped into 3 classes. Logs having no rootwad attached were generally found to have larger scour and deposition volumes, with an exception of logs parallel to flow, followed by those with logs attached at the downstream end and logs attached at the upstream end. At the same log orientation, the placement of the rootwad dictates the scour volumes. Having rootwad attached at the upstream end for logs oriented parallel to flow yielded more scour volumes than when logs were attached at the downstream. On the contrary the opposite is true for logs oriented oblique to flow. Further investigations are necessary to conduct in depth dynamics of these log pieces, and to further explore the different ratios between rootwad and log lengths.

\section{References}

1 West, A.J.; Lin, C.W.; Lin, T.C.; Hilton, R.G.; Liu, S.H.; Chang, C.T.; Lin, K.C.; Galy, A.; Sparkes, R.B.; Hovius, N. "Mobilization and Transport of Coarse Woody Debris to the Oceans Triggered by an Extreme Tropical Storm." Limnol Oceanogr, 56, 77-85, (2011).

2 Ruiz-Villanueva, V.; Díez-Herrero, A.; Bodoque, J.M.; Bladé, E. "Large Wood in Rivers and Its Influence on Flood Hazard." Geographical Research Letters, 40, 18, (2014).

3 Bocchiola, D.; Rulli, M.C.; Rosso, R. "Flume Experiments on Wood Entrainment in Rivers." Advances in Water Resources, 29, 1182-1195, (2006).

4 Piégay, H. Dynamics of Wood in Large Rivers. In The Ecology and Management of Wood in World Rivers, Gregory, S.; Boyer, K.; Gurnell, A.M., Eds. American Fisheries Society Symposium: Vol. 37. 119-113, (2003).

5 Wohl, E.; Beckman, N. "Controls on the Longitudinal Distribution of ChannelSpanning Logjams in the Colorado Front Range, USA." River Research and Applications, 30, 112-131, (2014).

6 Wohl, E. "Bridging the Gaps: An Overview of Wood across Time and Space in Diverse Rivers." Geomorphology, 279, 3-26, (2017).

7 Collins, B.D.; Montgomery, D.R.; Fetherston, K.L.; Abbe, T.B. "The Floodplain Large-Wood Cycle Hypothesis: A Mechanism for the Physical and Biotic Structuring of Temperate Forested Alluvial Valleys in the North Pacific Coastal Ecoregion." Geomorphology, 139-140, 460-470, (2012).

Braudrick, C.A.; Grant, G.E. "When Do Logs Move in Rivers?" Water Resources Research, 36, 571-583, (2000). 
9 Crosato, A.; Rajbhandari, N.; Comiti, F.; Cherradi, X.; Uijttewaal, W.S.J. "Flume Experiments on Entrainment of Large Wood in Low-Land Rivers." Journal of Hydraulic Research, 51, 1-8, (2013).

10 Iroumé, A.; Mao, L.; Andreoli, A.; Ulloa, H.; Ardiles, M.P. "Large Wood Mobility Processes in Low-Order Chilean River Channels." Geomorphology, 228, 681-693, (2015).

11 Henshaw, A.J.; Bertoldi, W.; Harvey, G.L.; Gurnell, A.M.; Welber, M. In Large Wood Dynamics Along the Tagliamento River, Italy: Insights from Field and Remote Sensing Investigations, Cham, 2015; Springer International Publishing: Cham. 151-154.

12 Braudrick, C.A.; Grant, G.E. "Transport and Deposition of Large Woody Debris in Streams: A Flume Experiment." Geomorphology, 41, 263-283, (2001).

13 Davidson, S.L.; MacKenzie, L.G.; Eaton, B.C. "Large Wood Transport and Jam Formation in a Series of Flume Experiments." Water Resources Research, 51, 10065-10077, (2015).

14 Shao, L.Y.; Chen, W.-F.; Yen, T.-M. "Study of Evaluating Model on Intercepted Volume of Driftwoods." Quarterly Journal of Forest Research, 30, 53-63, (2008).

15 Bertin, S.; Friedrich, H. "Measurement of Gravel-Bed Topography: Evaluation Study Applying Statistical Roughness Analysis." Journal of Hydraulic Engineering, 140, 269-279, (2014).

16 Allen, J.B.; Smith, D.L. "Characterizing the Impact of Geometric Simplification on Large Woody Debris Using Cfd." International Journal of Hydraulic Engineering, 1, 1-14, (2012). 